\title{
Comentário II: \\ cuidado com o outro nos museus: um novo paradigma
}

\section{Comment II:}

Caring for the other in museums: a new paradigm

htps://doi.org/10.1590/1982-0267202 1v29e32

\section{MYRIAN SEPÚLVEDA DOS SANTOS'}

https://orcid.org/0000-0002-321 5-4042

Universidade do Estado do Rio de Janeiro / Rio de Janeiro, RJ, Brasil

Oartigo "Curadoria em museus de história", de Vânia Carneiro de Carvalho, Paulo César Garcez Marins e Solange Ferraz de Lima, traz à tona uma questão candente ao mundo dos museus. Em 1960 o Conselho Internacional de Museus (lcom) patrocinou uma reunião celebrada na Polônia sobre os museus de história. A principal questão foi a disparidade entre a abordagem predominante na historiografia, orientada para o estudo dos fatos econômicos, sociais e culturais, e aquela presente na maioria dos museus de história, que permaneciam fiéis à exaltação de grandes heróis, fatos e eventos. Atualmente nos encontramos diante do mesmo problema.

Estudos acadêmicos, acompanhando os movimentos sociais, questionam as grandes narrativas historiográficas, vinculadas ao discurso de construção da nação, e, a partir de um estudo sistemático, têm mobilizado novas vozes e perspectivas que permitem compreender a construção do país, revisando diversas teses que apontavam o caráter pacífico, harmônico, evolutivo e pouco violento do povo brasileiro. Essas novas abordagens mostram o protagonismo, a resistência e a luta por parte daqueles que foram escravizados, denunciam o genocídio dos povos indígenas e sua contínua

\begin{abstract}
1. Professora associada da Universidade do Estado do Rio de Janeiro (Uerj). Coordenadora do Grupo de Pesquisa registrado no Conselho Nacional de Desenvolvimento Científico e Tecnológico (CNPq) Arte, Cultura e Poder e do Museu Afrodigital Rio. Doutora em sociologia pela New School for Social Research. Mestra em sociologia pelo Instituto Universitário de Pesquisas do Rio de Janeiro (Iuperj). Bacharel em história pela Universidade Federal Fluminense (UFF). Desenvolveu pesquisas de pós-doutorado no Centro de Estudos Latino-Americanos (University of Cambridge), no Centro de Pesquisa sobre Relações Sociais (Université de Paris V) e no Centro de Estudos Sociais (Universidade de Coimbra). E-mail:<myrian@uerj.br>.
\end{abstract}


2. Cf. Schwarcz (2019), Azevedo (1987), Castro (1995), Santos, Teles e Teles (2009).

3. Cf. Huyssen (1995).

4. Ver, entre outros, Bennett (1994), Poulot (1997), Witter e Barbuy (1997), Brefe (2003) e Santos (2006).

5. Cf. Brefe (2003). opressão, desfazem o mito de que a ditadura militar foi mais branda no Brasil do que em outros países da América Latina, apontam os vínculos entre passado e presente, e enfatizam a importância de medidas reparatórias. ${ }^{2}$

O que podem fazer os museus de história diante da reviravolta pela qual estamos passando? As grandes instituições, como o Museu Histórico Nacional e - Museu Paulista, passaram as últimas duas décadas do século passado desfazendo-se do acervo militarista, expansionista e elitista. Novos objetos foram adquiridos, maquetes foram construídas e representações foram refeitas para acompanhar narrativas que continham elementos econômicos, sociais e culturais inerentes às formações nacionais. Ainda há que se considerar o surgimento de movimentos negacionistas e de tentativas explícitas de falsificação da história, numa era caracterizada por muitos como de exaltação à memória, devido à promessa de guarda quase infinita de dados proporcionada pelas novas tecnologias de informação e pela multiplicação de arquivos, museus, monumentos, biografias, romances e filmes históricos. ${ }^{3}$

\section{DOS DILEMAS DE ACERVOS FETICHIZADOS}

O primeiro passo dado pelos autores foi justamente voltar às origens do significado de um museu de história, na seção intitulada "Dos dilemas de acervos sem história". Com base em estudos realizados sobre o surgimento dos museus de história, os autores abordaram diversos tipos de museus, enfatizando a relação entre suas propostas e seus respectivos acervos. Em uma exposição extensiva foram analisados o Musée des Monuments Français, que a partir da preservação de objetos como em um gabinete de curiosidades configurou uma contranarrativa à ruptura com o passado, que havia sido processada pelas lideranças da Revolução Francesa; o Musée de Cluny, já ambientado em period rooms, no qual se reconstituíam cômodos como se estivessem congelados no tempo; o Palácio de Versalhes, que utilizou extensivamente pinturas históricas como forma de narrar o passado; e os living museums norte-americanos, em que ambientes ao ar livre eram encenados.

Em relação a esses museus, diversos autores criticaram os discursos teleológicos, saudosistas, triunfalistas e homogeneizantes da história. ${ }^{4}$ São críticas que representaram a primeira grande guinada da história nos anos 1960. A seleção feita dos museus citados como exemplares de relações travadas entre narrativas históricas e modos de apropriação e exposição de objetos também aparece em outros estudos. ${ }^{5}$ 
A novidade desta análise é a crítica à coexistência entre objetos autênticos, recriações do passado e a solução encontrada. Os objetos foram considerados "sem história" por terem sido descontextualizados, ou seja, por terem sido retirados de seu contexto original e inseridos em um museu de história. Certamente a crítica é correta ao apontar que os objetos musealizados adquirem significados relacionados às ideias e intenções daqueles que os selecionaram, classificaram e organizaram em sua exposição. Há aqui três observações a serem feitas.

Em primeiro lugar, a crítica deve ser direcionada não apenas aos museus triunfalistas do século XIX e início do século XX, mas também aos museus modernos que, com base em uma ciência histórica, procuraram objetos para ilustrar o desenvolvimento econômico, político e social. As novas propostas desenvolvidas tanto pelo Museu Histórico Nacional como pelo Museu Paulista continuaram a utilizar objetos destinados a ilustrar as ideias e intenções dos produtores de discursos dos respectivos museus, fossem eles autênticos ou não. A exposição do Museu Histórico Nacional, "Colonização e dependência", citada no artigo, embora troque os heróis por ciclos econômicos, faz parte de uma história-síntese, linear, contínua, com largo uso de objetos fetichizados. ${ }^{6}$ Todo e qualquer objeto retirado de seu contexto de origem e que passa a ser exposto em um museu, ou mesmo a fazer parte de uma coleção particular, é descontextualizado e adquire propriedades de um semióforo que contém significados livres da funcionalidade prática.

A segunda observação é a de que os objetos, mesmo descontextualizados, têm uma história que é justamente a do percurso percorrido entre o lugar onde se encontravam e as exposições. Ulpiano Bezerra de Meneses, ao realizar a "desdocumentalização do documento", nos apresenta a história dos objetos, analisando sua "biografia social". A análise da trajetória dos objetos desde o pertencimento às suas redes sociais até a chegada ao museu é um fazer histórico. $\bigcirc$ Museu Paulista traz com ele muitas histórias a serem contadas.

A terceira e última observação ao conteúdo dessa primeira parte do artigo diz respeito às análises realizadas sobre os museus históricos franceses e norteamericanos. Os modelos europeus tiveram muita influência na organização dos museus brasileiros, mas estes precisaram se adequar às tensões internas, responsáveis também por rumos tomados pela historiografia, em razão de sua relação com os objetos expostos e com o público. Não podemos compreender as narrativas nacionais apenas com base nos modelos estrangeiros. É preciso compreender as relações de poder entre nações e seu impacto na configuração e trajeto dos museus históricos brasileiros. As diferenças são muito grandes também quando se comparam as relações dos museus com o público, o que é essencial para atender ao desafio proposto de problematizar a noção de curadoria. 
7. Cf. Witter e Barbuy (1997).

8. Bourdieu (1979).

\section{CULTURA MATERIAL E HISTÓRIA: UMA POSSIBILIDADE DE RENOVAÇÃO}

desafio proposto pelos autores do artigo de historicizar a cultura material deve ter início com a história da construção do Museu Paulista, que é extremamente interessante porque nos mostra, por um lado, como símbolos são apropriados e reapropriados, sendo atribuídos a eles diversos significados. Por outro lado, ela torna evidente que símbolos transcendem significados atribuídos, sendo mais bem compreendidos como resultado de disputas complexas ocorridas ao longo do tempo no campo da cultura.

A criação do Museu do lpiranga tem sido objeto de estudos interdisciplinares, em grande medida realizados como parte das atividades do próprio museu. ${ }^{7}$ A ideia de construção de um monumento para celebrar a independência surgiu em 1885, ainda no período do Império. A obra foi finalizada pelo governo do estado de São Paulo, já na República. O local escolhido era repleto de simbolismo: o topo da colina do Ipiranga, próximo ao riacho homônimo, onde, conforme a letra consagrada no Hino Nacional, D. Pedro I teria proclamado a Independência. A casa do Museu Paulista é, portanto, uma homenagem à independência do Brasil de um país europeu, Portugal.

Se o museu tem uma história, ele também é o palco onde essa história é contada. Os museus nacionais ocupam prédios imponentes que têm o poder de reivindicar reverência de seus visitantes. As salas, corredores e legendas indicam o ritmo do passo a ser dado e o comportamento contido. Para o sociólogo Pierre Bourdieu, os museus são uma fonte de capital cultural e proporcionam distinção àqueles que dominam seus códigos. ${ }^{8}$ Mas sabemos que no Brasil são poucos os que têm suas chaves. A região do lpiranga já era uma referência relevante para os antigos paulistanos, pois foi um local importante na fundação da cidade. projeto arquitetônico escolhido, de estilo eclético neoclássico, utilizou detalhes da antiga arquitetura greco-romana, como grandes colunas, pórticos e mármores. Há um contraste evidente entre o prédio e as edificações paulistanas mais simples, influenciadas pelas técnicas portuguesas, de forma que o primeiro impacto causado pelo monumento da Independência pode ser o afastamento do visitante. Para aquele desavisado que chega aos jardins do "palácio" em um feriado, as perguntas são muitas. Que prédio é esse? Quem o construiu? Com que objetivo? $\bigcirc$ que ele tem a me dizer? Quem eram os interessados em celebrar a Independência e qual a relação do aclamado grito do Ipiranga com os dias atuais?

Essas respostas podem estar em uma fase do Museu Paulista que tem sido esquecida. A proposta de glorificar D. Pedro I por meio do memorial foi 
abandonada pelo projeto naturalista. $\bigcirc$ alemão Hermann von Ihering dirigiu o museu entre 1894 e 1916, imprimindo na instituição uma forte vocação pelo estudo e pesquisa na área da história natural. As coleções de botânica e zoologia só foram transferidas para o Museu de Zoologia em 1939 e o acervo etnográfico para o Museu de Arqueologia e Etnografia em 1989.

A relação entre os museus e os projetos nacionais tem sido objeto de vários estudos. ${ }^{9}$ Grandes museus como o Louvre e o Museu Britânico, bem como o Museu Nacional, o Museu Paulista ou o Museu Histórico Nacional, construíram imaginários sociais que ensejaram sentimentos comuns entre os membros de uma nação. Uma das características de suas coleções foi a condição de permanência que, segundo Pomian, estaria vinculada ao fato de que os objetos teriam como referência não apenas o colecionador e o momento presente, mas a ciência e gerações futuras. ${ }^{10}$ Essas construções coletivas respaldadas pelo uso de farta cultura material nos dizem muito sobre os projetos nacionais e sobre as relações que se formavam entre nações.

A partir do século XVIII algumas nações europeias, paralelamente às invasões expansionistas, organizaram expedições arqueológicas em busca de antiguidades clássicas. Os objetos e obras de arte da Grécia e de Roma eram disputados e conferiam imenso prestígio às nações que os possuíam. As colônias também forneceram obras de arte e até blocos arquitetônicos inteiros. $\bigcirc$ Louvre e - Museu Britânico foram constituídos como museus universais, expressando o poder de cada um dos impérios que se formavam. No século XIX o Brasil teve seu Império e seu Museu Real, que foi criado em 1818. Embora tenha incorporado a coleção Fiengo, com múmias do Egito e peças de Herculano e Pompeia, que foram trazidas pela futura imperatriz Teresa Cristina, o museu foi criado e se consolidou como um museu de história natural. Algumas coleções de história natural também fizeram parte dos grandes museus europeus, mas logo se separaram para fazer parte de museus específicos da área. É significativo que os principais museus nacionais de um país tenham sido construídos como museus de história natural. No século XIX grandes viagens exploratórias para a América Latina foram realizadas por europeus com o intuito de classificar itens da flora e fauna do continente. Essas expedições foram fundamentais para o desenvolvimento das ciências da natureza e de seus museus, bem como para a exploração das riquezas naturais do continente. ${ }^{11} \bigcirc$ imaginário que se construiu sobre a riqueza natural do Brasil, que leva em seu nome esse símbolo, existe ainda hoje, seja no saber popular, seja nas atuais atividades econômicas de exportação de commodities.

Além do Museu Real, posteriormente chamado de Museu Nacional, o Museu Paraense, o Museu do Estado, o Museu Paranaense, o Museu Mineiro, o Museu Júlio de Castilhos e o Museu Mariano Procópio tiveram importantes coleções
9. Cf. Bennett (1995), Duncan (1997), Poulot (1997), Boswell e Evans (1999).

10. Pomian (1990, p. 44).

11. Cf. Santos (2013-2014). 
12. Cf. Lopes (1998). Segundo a autora, o naturalista prussiano Rudolph Amando Philippi dirigiu o Museu Nacional de Santiago do Chile entre 1853 e 1896; o paleontólogo e zoólogo Karl Hermann Konrad Burmeister, também prussiano, dirigiu o Museu Nacional de Buenos Aires entre $1862 \mathrm{e}$ 1892. Após sua morte, foi sucedido pelo zoólogo russo Carlos Berg, que fora anteriormente diretor do Museo Nacional de Montevideo. O naturalista alemão Adolfo Ernest organizou o Museo Nacional da Venezuela em 1874; o zoólogo inglês Edwyn Reed dirigiu o Museo de Historia Natural, em Valparaíso, fundado em 1876; o suíço Henri Pittier participou da organização dos museus da Costa Rica e Venezuela.

13. Brefe, op. cit., p. 97.

14. Ver, sobre o tema, a declaração de Taunay (1946) segundo a Washington Luís teria incentivado decisivamente a Seção de História do museu. de história natural. $\bigcirc$ grande número de naturalistas europeus dirigindo museus não só brasileiros, mas também latino-americanos, indica a dimensão do peso políitico desse projeto. ${ }^{12}$ Embora o diretor do Museu Nacional de meados do século XIX fosse brasileiro, Ladislau de Souza Mello Netto se formara em Paris e mantinha vínculos estreitos com a comunidade científica europeia. Contratou inúmeros naturalistas estrangeiros para dirigirem as diversas seções da instituição. Dois desses cientistas, o suíço Emílio Goeldi e o alemão Hermann von Ihering, tornaram-se, mais tarde, diretores do Museu Paraense e do Museu Paulista, respectivamente.

O Museu Paulista, dirigido por von lhering, não só classificava e fornecia minérios e exemplares da flora e fauna para as coleções de museus europeus, mas o próprio diretor defendia em publicações científicas a exterminação dos povos indígenas brasileiros por considerá-los um empecilho para o desenvolvimento e progresso. ${ }^{13}$ As pesquisas antropológicas dessa época se dedicavam ao estudo comparativo de crânios e esqueletos de seres humanos, que eram classificados de acordo com uma escala evolutiva. Os não europeus eram considerados racialmente inferiores e a mestiçagem era tida como responsável pela degeneração da raça branca. Os museus de história natural exerceram um importante papel político ao influenciarem o debate sobre segregação racial à época.

Nos anos 1920, o Brasil republicano já procurava para si um novo desenho. A partir de 1917 o Museu Paulista, apesar de manter suas coleções de história natural, voltou-se para a construção da história da nação, com a nomeação do novo diretor, Affonso d'Escragnolle Taunay. As publicações do corpo do Museu Paulista sobre esse período, desconstruindo inclusive o importante projeto iconográfico da época, não necessitam ser repetidas, mas é importante destacar a qualidade e a acuidade das análises.

É relevante, contudo, debater com o público as relações de poder travadas para que um novo imaginário se impusesse, lembrando sempre que a maior parte da população não participava desse debate. Em um momento em que o movimento negro se fortalece como movimento identitário, em que povos indígenas denunciam a continuidade da segregação e morte, em que as questões ambientais se chocam com a economia das grandes criações de gado, e em que as estátuas de bandeirantes são colocadas em questão pela grande mídia, passado e presente se aproximam, de forma que os museus têm muito com o que contribuir.

A proposta historiográfica de Taunay foi apoiada pelos presidentes do estado de São Paulo, Altino Arantes (1916-1920) e por Washington Luís Pereira de Souza (1920-1924), e novamente por este último quando eleito presidente da República (1926-1930). ${ }^{14}$ A substituição do discurso abertamente racista de von 
Thering pela defesa dos bandeirantes, que exemplificavam a mestiçagem e a conquista do território brasileiro, expressou a vitória dos segmentos paulistas tradicionais que procuravam marcar, por meio de doações de pertences pessoais, seu lugar na construção do estado e da nação.

É interessante observar que em um curto período surgiu um outro projeto de nação, que, embora rejeitado pelos republicanos positivistas, foi apoiado pelo presidente Epitácio Pessoa e por importantes famílias que pertenciam às elites nacionais. Estava em disputa o mito fundador para a nova República. O Museu Histórico Nacional foi criado em 1922, no Rio de Janeiro, sob a direção de Gustavo Barroso, que liderou a instituição por quase quarenta anos. Nesse museu a figura mítica de João Ramalho e as entradas de colonização e povoamento do período colonial não tiveram muito espaço, uma vez que as atenções estavam voltadas para os imperadores brasileiros e para as grandes batalhas travadas na Guerra do Paraguai. $\bigcirc$ "museu-memória" priorizou o culto aos objetos autênticos do passado, que eram as armas, as moedas e as medalhas, em grande profusão. O famoso pátio dos canhões dispunha as peças ao redor de uma praça quadrada, causando grande impacto pelo número e potência de um objeto associado à guerra. Ainda assim, também foram utilizados grandes painéis com pinturas históricas, estátuas e monumentos. Contribuíram para a encenação do passado objetos doados por famílias tradicionais, muitas identificadas com a extinta nobreza. Sempre em grande quantidade, as carruagens, louças com brasões e mobiliário importado ocupavam inúmeras salas. Comprometido com o Partido Integralista e defendendo uma ideia de nação militarista e saudosa do poder absoluto dos imperadores, Barroso exerceu enorme poder na museologia, estando à frente do único curso de museus da época, no qual tinha por responsabilidade organizar os currículos e ministrar as aulas de história militar. ${ }^{15}$

Em comum entre esses dois museus e as centenas de museus de história que se espalharam pelo território brasileiro havia a celebração das elites políitica e econômica, a ausência de conflitos inerentes à dominação exercida e o uso celebrativo de objetos para reforçar emoções e narrativas. Voltamos, portanto, à reunião sobre museus históricos, patrocinada pelo lcom em 1960, e para as propostas de construção na museologia de novas narrativas e políticas de aquisição de acervo.

Alguns avanços foram mencionados merecem ser reiterados. A desconstrução dos discursos celebrativos e a desfetichização dos objetos selecionados como detentores de propriedades mágicas geraram uma renovação dos museus, que passaram a estar mais próximos das diversas demandas e conflitos sociais. Nesse sentido, observamos uma mudança radical nas propostas curatoriais e nos módulos expositivos tanto do Museu Histórico Nacional como do Museu Paulista. 
16. Benjamin (1987).

17. Cf. Sodaro (2019).
Principalmente após os anos 1980, a advertência feita por Walter Benjamin de que todo documento de cultura é um documento da barbárie tem sido levada a sério. ${ }^{16}$ Os museus, de modo geral, abriram suas portas para abrigar uma diversidade maior do que aquilo que se compreende como cultura material, procurando representar segmentos sociais antes ausentes desses espaços culturais. Mais do que isso, os museus partiram para a formação de curadorias e coleções colaborativas, em que o "outro" que é apresentado deixa de ser o objeto do museu e passa a ser o autor de sua própria representação. Museus se diversificaram e alcançaram novas pautas. Diversas formas de opressão ao longo da história e ao redor do mundo passaram a ser objeto da história e da memória, como a escravidão dos africanos no período colonial, o genocídio dos povos indígenas, as ditaduras militares da América Latina, o Holocausto, o apartheid sul-africano e o genocídio de Ruanda, entre outras barbáries. Arquivos, museus, bibliotecas, sítios históricos, bem como filmes, performances e instalações artísticas voltaram-se para as histórias difíceis de serem narradas. $\bigcirc$ foco deixou de ser a representação do passado e se tornou a procura da justiça. ${ }^{17}$

Os museus, portanto, enfrentam novos desafios. História e memória se confundem e as certezas do passado, construídas por um aparato legitimador utilizado por arquivos, filólogos, bibliotecas e museus, têm sido colocadas em questão. A historiografia, ao se voltar para aqueles que não tinham voz no espaço público, mobilizou novos atores, novas denúncias de exploração e exclusão, bem como novas metodologias de acesso a eventos vivenciados. $\bigcirc$ Brasil apresenta desafios específicos por ser um dos países com os maiores índices de desigualdade social e econômica do mundo, abismo que se aprofunda por meio de formas de opressão não aparentes e de crises sociais e econômicas. Os museus, bem como diversas outras práticas culturais, continuam a ser domínio de segmentos privilegiados da sociedade. As novas tecnologias de informação e comunicação, que surgiram com a proposta de democratização de discursos e inclusão social, hoje apresentam riscos em razão da falta de controle sobre seu uso, da dificuldade de acesso, do automatismo gerado em alguns de seus processos, e por permitir a manipulação de desejos em grande escala.

Quanto à relação entre cultura material e história, não há um caminho único. Tendo em vista uma ênfase maior conferida às estruturas da linguagem, a partir dos anos 1980, passou-se a considerar não apenas histórias e memórias como construções sociais que entram em conflito, mas também que se reproduzem com certa autonomia em relação a seus agentes. Além disso, críticas importantes começaram a questionar a capacidade que temos atualmente de aprender com e dar sentido ao passado. Dentro de um campo interdisciplinar amplo, diversas foram 
as críticas ao presentismo atual, à perda de sentido de historicidade e ao mundo amnésico que se constitui em meio ao abuso da memória. ${ }^{18}$

Os conceitos de cultura material, história ou memória não são totalizantes e não se resumem a um único sentido; muito pelo contrário, eles têm se fragmentado em uma pluralidade de sentidos. Há diferenças epistemológicas e mesmo ontológicas no lidar com o conceito de cultura material, uma vez que o ponto de inflexão é a razão humana. Somos seres racionais ou irracionais? Conferimos sentido às coisas, ainda que elas adquiram certa autonomia em relação às atribuições dadas: ou as coisas podem ser pensadas como autoras e responsáveis pelo seu trajeto? No trabalho clássico do antropólogo George W. Stocking Jr., os objetos e museus fazem parte de contextos mais amplos; para Arjun Appadurai, também antropólogo, a cultura material dá significado à vida e há uma relação entre a vida das coisas e a vida das pessoas; por sua vez, para o filósofo Bruno Latour, os objetos são agentes, autores e responsáveis pelos acontecimentos. ${ }^{19}$ Assim, não há um conceito único de cultura material, como também não há de tempo, história ou memória. ${ }^{20}$

Em suma, podemos dizer que os autores estão no caminho certo, procurando ampliar e debater o que quer que sejam as atividades curatoriais, em todos os seus processos de coleta, identificação, processamento e difusão. $\bigcirc$ desafio é grande, mas, apesar de tantas incertezas, a sensibilidade e vontade de justiça em relação aos silenciados, àqueles que são estigmatizados e, principalmente, aos excluídos, têm se mostrado presente.
18. Cf. Sarlo (2007), Hartog (2015), Huyssen. op. cit.

19. Stocking Jr. (1985), Appadurai (1986), Latour (2012).

20. Cf. Santos (2020). 


\section{REFERÊNCIAS}

LIVROS, ARTIGOS E TESES

APPADURAI, Arjun. The social life of things: commodities in cultural perspective. Cambridge: Cambridge University Press, 1986.

AZEVEDO, Célia Maria Marinho. Onda negra medo branco: o negro no imaginário das elites: século XIX. Rio de Janeiro: Paz e Terra, 1987.

BENJAMIN, Walter. Sobre o conceito de história. In: Obras escolbidas: volume 1: magia e técnica, arte e política: ensaios sobre literatura e história da cultura. São Paulo: Brasiliense, 1987. p. 222-232.

BENNETT, Tony. The birth of the museum: history, theory, politics. London: Routledge, 1995.

BOSWELL, David; EVANS, Jessica. Representing the nation: a reader: histories, heritage and museums. London: Routledge, 1999.

BOURDIEU, Pierre. La distinction. Paris: Éditions de Minuit, 1979.

BREFE, Ana Claudia Fonseca. O Museu Paulista: Affonso Taunay e a memória nacional: 19171945. São Paulo: Editora Unesp, 2003.

CASTRO, Hebe Maria. Das cores do silêncio: os significados da liberdade no Sudeste escravista. Rio de Janeiro: Arquivo Nacional, 1995.

DUNCAN, Carol. Civilizing rituals: inside public art museums. London: Routledge, 1997.

HARTOG, François. Regimes de historicidade: presentismo e experiência do tempo. Belo Horizonte: Autêntica, 2015.

HUYSSEN, Andreas. Twilight memories: marking time in a culture of amnesia. London: Routledge, 1995.

LATOUR, Bruno. Reagregando o social: uma introdução à teoria do ator-rede. Salvador: Edufba, 2012.

LOPES, Maria Margaret. O Brasil descobre a pesquisa científica: os museus e as ciências naturais no século XIX. São Paulo: Hucitec, 1998. 
POMIAN, Krzysztof. Collectors and curiosities: Paris and Venice, 1500-1800. Cambridge: Polity Press, 1990.

POULOT, Dominique. Musée, nation, patrimoine (1789-1815). Paris: Gallimard, 1997.

SANTOS, Cecília MacDowell; TELES, Edson; TELES, Janaína de Almeida. Desarquivando a ditadura: memória e justiça no Brasil. São Paulo: Hucitec, 2009. v. 1-2.

SANTOS, Myrian Sepúlveda dos. A escrita do passado nos museus históricos. Rio de Janeiro: Garamond/MinC/Iphan, 2006.

SANTOS, Myrian Sepúlveda dos. Naturalists in nineteenth-century Brazil. Archiv Weltmuseum Wien, Vienna, v. 63-64, p. 38-59, 2013-2014.

SANTOS, Myrian Sepúlveda dos. O retorno do pesadelo da amnésia coletiva. Revista Crítica de Ciências Sociais, Coimbra, v. 121, n. 1, p. 103-122, 2020.

SARLO, Beatriz. Tempo passado: cultura da memória e guinada subjetiva. São Paulo: Companhia das Letras, 2007.

SCHWARCZ, Lilia Moritz. Sobre o autoritarismo brasileiro. São Paulo: Companhia das Letras, 2019.

SODARO, Amy. Museus memoriais: a emergência de um novo modelo de museu. PerCursos, Florianópolis, v. 20, n. 44, p. 207-231, 2019. Doi: <https://doi.org/10.5965/19847246204420 19207>.

STOCKING JR., George (ed.). Objects and others: essays on museums and material culture. Madison: The University of Wisconsin Press, 1985.

TAUNAY, Affonso d'Escragnolle. Comemoração do cincoentenario da solene Instituição do Museu Paulista no Palácio do Ipiranga. São Paulo: Imprensa Oficial do Estado, 1946.

WITTER, José Sebastião; BARBUY, Heloisa (orgs.). Museu Paulista: um monumento no Ipiranga: história de um edifício centenário e da sua recuperação. São Paulo: Federação e Centro das Indústrias do Estado de São Paulo, 1997.

Artigo apresentado em: 11/01/2021. Aprovado em: 30/01/2021.

\section{(cc) BY}

